\title{
Clinical Evaluation of Maxillary Arch Complete Denture Impressions Made by Undergraduate Students in a Dental College
}

\author{
Sharma $\mathrm{R}^{1}$, Bhochhibhoya $\mathrm{A}^{2}$, Acharya $\mathrm{B}^{3}$, Rana $\mathrm{SB}^{4}$, Sagtani RA ${ }^{5}$ \\ ${ }^{1,4}$ Lecturer, Department of Prosthodontics, College of Dental Sciences and Hospital \\ Nepal Medical College, Attarkhel, Jorpati \\ ${ }^{2}$ Assistant Professor, Department of Prosthodontics, College of Dental Sciences and Hospital \\ Nepal Medical College, Attarkhel, Jorpati \\ ${ }^{3}$ Professor, Department of Prosthodontics, College of Dental Sciences and Hospital \\ Nepal Medical College, Attarkhel, Jorpati \\ ${ }^{5}$ Assistant Professor, School of Public Health, Patan Academy of Health Sciences
}

\begin{abstract}
Introduction: An accurate impression is the foundation of denture fabrication process thus a practitioner should be aware of the possibility of including errors during this procedure. Time spent in making a good impression will reduce the time required in adjusting the final prosthesis as well as make it more comfortable for the patient in accepting the prosthesis.

Materials and Methods: Maxillary arch final impressions made by undergraduate dental students on 106 edentulous patients were evaluated. The impressions were assessed on the basis of criteria's like errors on mixing, flow, tray positioning, presence of voids, creases/irregularities, exposure of tissue stops and extension at posterior border. The data's collected were analyzed for the frequency of occurrence and distribution of each type of errors.

Results: It was found that $97.2 \%$ of students performed at least one detectable error during making of maxillary arch final impression. The number of errors made by students ranged from single to as much as seven errors in one impression. The most common error was lack of exposure of all tissue stops followed by presence of voids and creases/irregularities on impression surface.

Conclusion: There is high possibility of including errors while making maxillary arch final impression by undergraduate dental students. The study highlights the need to explore novel techniques of clinical demonstrations and teaching important concepts to learning students. The inclusion of more pre-clinical exercises in undergraduate curriculum relating to manipulation of dental materials may improve skills of students in making accurate edentulous impressions.
\end{abstract}

Key words: Complete denture; edentulous patients; final impression; maxillary impression

\section{Introduction}

$\mathrm{T}$ he accurate recording of final impression is one of the important milestones in fabrication of complete dentures. Impressions interpret the clinical situation to laboratory

Conflict of Interest: No

\section{*Corresponding Author}

\section{Dr. Rinu Sharma}

Lecturer

Department of Prosthodontics, College of Dental

Sciences and Hospital

Nepal Medical College,Kathmandu, Nepal

Email:dr.sharmarinu@gmail.com personnel, allowing them to fabricate accurate and representative casts. The accuracy of impression directly relates to the adaptation of denture to oral mucosa, which in turn reflects the success of complete denture. ${ }^{1}$ Factors describing success in the long run such as retention, stability, support, esthetics as well as preservation of the underlying residual ridges are mostly determined at the stage of making impression. $^{2}$

The accurate impressions record both the anatomy as well as the function of denture bearing foundation. According to the British 
Society for the Study of Prosthetic Dentistry (BSSPD) recommendations, a complete denture impression 'should record the entire functional denture-bearing area to ensure maximum support, retention and stability for the denture during use'. The maxillary arch impression should extend posteriorly to the hamular notches and just beyond the junction of hard and soft palates. It should also show intact record of frena together with rounded labial and buccal sulci. ${ }^{3}$ However, this clinical procedure is skill dependent and operator variation largely affects the accuracy of records. Woelfel et.al ${ }^{4}$ compared maxillary final impression records made by seven dentists on same patient and found border variation of several millimeters. The greatest variation in border contour occurred in the region of the buccal frenum and other differences were in the thickness of the material over the posterior palatal seal area and variation in size and location of pressure areas.

Since definitive impression is the keystone of the denture prescribing process, the practitioner should be aware of the possibility of including errors during manipulation of materials and impression making procedure. These errors if incorporated require lot of operator's time in repeating the work; makes it troublesome for patients and also triggers dissatisfaction in them. Increased chair side time, which may be required for adjusting misfit of dentures, adds distress to the operator. Time spent in making a good impression will reduce the time required in adjusting the final prosthesis in the mouth as well as make it more comfortable for the patient in accepting the prosthesis. Different maxillary arch impressions made by undergraduate dental students in final year were clinically evaluated in this study. Since students are in the process of learning this skill, it facilitated identification of several possible errors. Though the possibility of making errors during this procedure cannot be completely over looked, but if potential errors are recognized and sorted out, incorporation of appropriate techniques could help minimize them.

\section{Materials and Methods}

Maxillary arch final impressions made by undergraduate dental students from 106 edentulous patients visiting department of prosthodontics, Nepal Medical College, were evaluated. The duration of data collection was from September 2018 till January 2019. Zinc oxide eugenol paste was utilized as final impression material for all the patients. The material was mixed according to the manufacturer's instructions and loaded into the thoroughly dried custom tray. Self- activated acrylic resin custom trays were fabricated with wax spacer and four tissue stops. After border molding was complete, wax spacer was removed and three vent holes were prepared in the midpalatal region of maxillary custom tray. Patient's mouth was prepared by wiping the tissues with gauze pads before placing the loaded tray. The tray was supported by single finger in the mid-palatal region during placement and after almost 60 to 90 seconds, when the setting paste reached the consistency to be molded; the finger was released to let the excess material escape through vent holes. Functional movements were then performed on each patients which included upward, outward and inward movements of upper lips and cheeks, forward and backward movements of buccal frenum, wide opening of the mouth, moving the mandible from side to side and asking patients to say "ah" for recording of posterior palatal seal area. The impression paste was provided sufficient flow time to ensure good tissue contact.

All these basic techniques were briefed to each operating students to maintain uniformity in procedure. After setting of the material, students were instructed to remove the impression from patient's mouth. Thus, the maxillary arch final impression made on first attempt for each patients were assessed on the basis of criteria's 
like errors on mixing of the material, adequate flow, correct tray positioning and presence of voids, creases/irregularities. Similarly the thickness of the material was also assessed both on labial/buccal flange area and also within the tray borders through exposure of tissue stops. The excessive pressure application on entire denture bearing area was also evaluated along with the extension at posterior borders. Thus collected data were examined for the frequency of occurrence and distribution of each type of errors.

\section{Results}

In this study, ten different types of errors while making maxillary arch final impressions were assessed. It was alarming to find that $97.2 \%$ of students performed at least one detectable error during making of final impression (Table 1).
The number of errors made by students ranged from single to as much as seven errors in one impression. Majority of the students however performed three to four detectable errors in this procedure (Table 1).

While analyzing the types of errors, it was found that the most common error made by undergraduate dental students was lack of exposure of all tissue stops $(65.1 \%$ in our study). Out of four tissue stops placed, Figure 1 shows exposure of a single tissue stop. The other common errors were found to be presence of voids and creases/irregularities on impression surface (Figure 2). The least common error was found to be under extension of the impression material. Figure 3 shows material over extension posteriorly. A description of different errors occurred and their frequencies appear in Table 1.

Table 1: Number of errors performed by under graduate students during impression making. $(\mathrm{n}=$ 106)

\begin{tabular}{|c|c|c|}
\hline Number of errors & Count (n) & Percent \\
\hline Zero & 3 & $2.8 \%$ \\
\hline One & 9 & $8.5 \%$ \\
\hline Two & 20 & $18.9 \%$ \\
\hline Three & 34 & $32.1 \%$ \\
\hline Four & 24 & $22.6 \%$ \\
\hline Five & 13 & $12.3 \%$ \\
\hline Six & 02 & $1.9 \%$ \\
\hline Seven & 1 & $0.9 \%$ \\
\hline At least one error & 103 & $97.2 \%$ \\
\hline
\end{tabular}

Table 2: Frequency distribution of the type of errors performed by students during maxillary arch impressions $(n=106)$

\begin{tabular}{|c|l|c|c|}
\hline S. No. & Type of errors & Frequency (n) & Percentage \\
\hline 1 & Mixing of material & 19 & $17.9 \%$ \\
\hline 2 & Voids & 49 & $46.2 \%$ \\
\hline 3 & Creases/Irregularities & 47 & $44.3 \%$ \\
\hline 4 & Flow & 19 & $17.9 \%$ \\
\hline 5 & Thick labial/ buccal flanges & 45 & $42.5 \%$ \\
\hline 6 & Exposure of tissue stops & 69 & $65.1 \%$ \\
\hline 7 & Excessive pressure areas & 29 & $27.4 \%$ \\
\hline 8 & Tray positioning & 17 & $16.0 \%$ \\
\hline 9 & Over extension posteriorly & 31 & $29.2 \%$ \\
\hline 10 & Under extension posteriorly & 6 & $5.7 \%$ \\
\hline
\end{tabular}




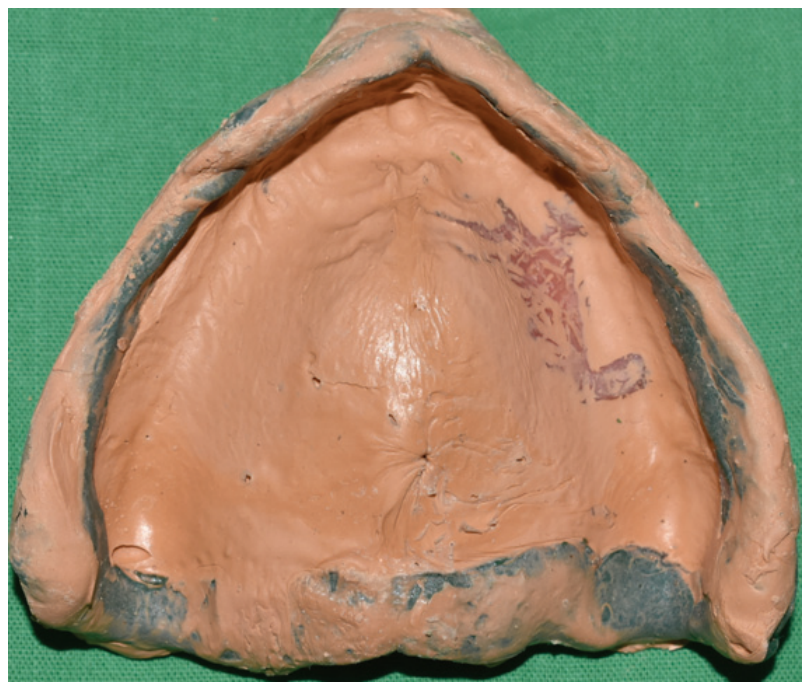

Figure 1: Showing exposure of single tissue stop

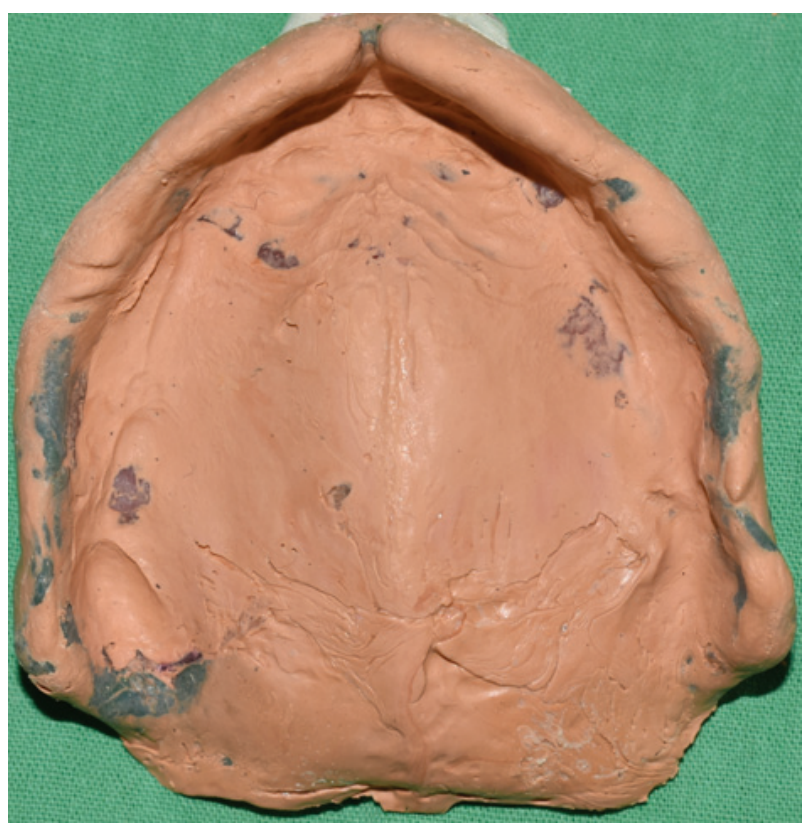

Figure 3.Posterior overextension of the impression material

\section{Discussion}

This study evaluated maxillary arch final impressions made by undergraduate dental students of final year. The impressions were made with Zinc Oxide Eugenol (ZOE) impression paste in border molded custom trays placing vent holes. According to a survey done in United Kingdom, the most commonly used final impression materials were found to be ZOE and Poly Vinyl Siloxane followed by Irreversible hydrocolloid, which was utilized by few practitioners. ${ }^{5}$ ZOE still remains preferred

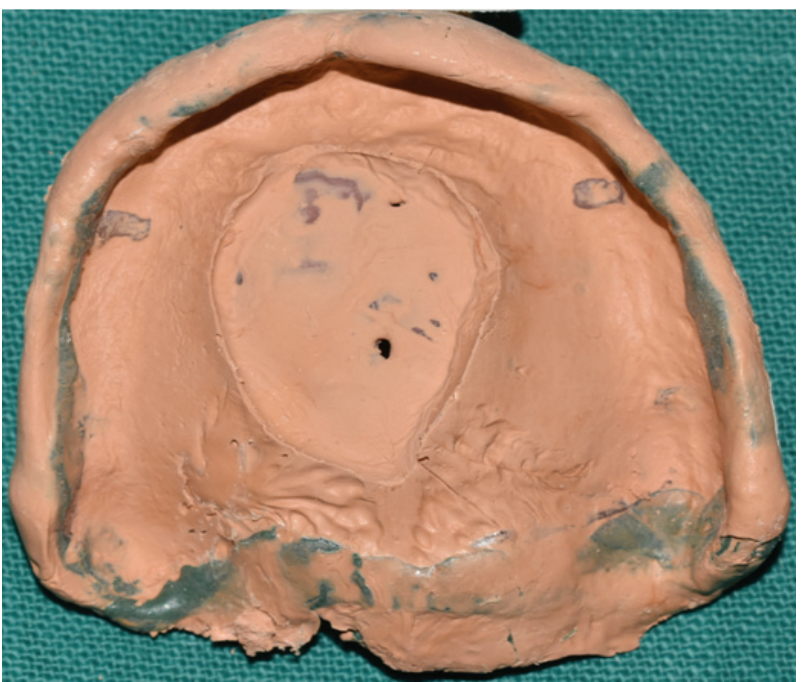

Figure 2. Presence of void in impression surface

material by many clinicians around the globe mainly because it is hygienic, economical and reproduces excellent surface details.

Petropoulos et.al. found that majorities of dental schools in United States, utilize modeling plastic impression compound for border molding the custom trays and the border-molded custom trays for recording of final impression, which provides appropriate extension covering denture-bearing tissues and helps maintain intimate and stable contact with them. Selective-pressure technique was the most utilized impression philosophy in their study however they found more than one third of the schools do not place vent holes in the final impression trays. ${ }^{6}$ Placing vent holes in the tray offers an escape route for the impression material and provides selective relief of pressure during impression making. ${ }^{7} \mathrm{~A}$ study done by Bhochhibhoya et.al, also found that majority of practitioners in Nepal, utilize ZOE for making final impression in auto-polymerizing acrylic resin made custom trays and preferred selective pressure impression philosophy. ${ }^{8}$

The impressions made by students were assessed on the basis of criteria like errors during mixing, flow of the material, positioning of the tray, thickness as well as extension of impression material. The most common error was found to be lack of exposure of all tissue stops, which signifies non-uniform thickness of material 
within the tray. When the tray is seated, the use of tissue stop helps to correctly orient the tray maintaining its stability in three dimensions. ${ }^{7}$ Yuchun et.al. evaluated final impression with and without placing tissue stops and found that the trays with tissue stops obtained the impression materials with relatively even thickness, which was close to $2 \mathrm{~mm}$ however in the trays without tissue stops, thicknesses appeared inconsistent in each area. ${ }^{9}$

Maxilla has a larger denture-bearing surface compared to mandible thus requiring greater pressure application into the tray for right placement of the tissues. This factor may also have contributed to increased thickness in labial/ buccal flanges, which accounted for $42.5 \%$ of errors in our study. If the pressure application is excessive, it could however result in pressure areas throughout the impression $(27.4 \%$ in our study) and leads to undue pressure transfer to the underlying tissues. Frank ${ }^{10}$ has stated that pressure in an impression can be controlled by tray design and material selection. In this study, trays with tissue stops and low viscosity material exhibited less pressure towards the tissues. Klein et.al have advocated use of clear acrylic resin tray in eliminating excessive displacement of tissues. Since the areas of blanching can be seen through the clear trays, such areas could be marked and relieved beforehand, getting rid of excessive pressure. ${ }^{11}$

The presence of voids, creases/irregularities on tissue surface was found to be the second most common error in our study. A meticulous reproduction of surface detail is significant in enhancing primary retention. Only then, there would be a close contact of the denture base with all the irregularities of tissues, resulting in a greater surface area covered. ${ }^{12}$ However, many clinical factors such as moisture on the tissues and secretions from gland, ${ }^{13}$ flabby alveolar ridge, ${ }^{14}$ and a patient's co-operation with the dentist could all affect the precision of an impression.
Similarly, on operator's part, improper seating and not maintaining stability of the trays until setting of impression material could add on to voids, creases/irregularities. Undergraduate students in this study did the mixing of material and loading of the trays by themselves. So, their inability to correlate the size of tray with the amount of material required could have resulted in overfilling the trays with impression material. This could then easily result in posterior overextension of impression material, which accounted for $29.2 \%$ of errors in our study. Also due to viscous nature of Zinc oxide eugenol impression paste, it requires vigorous mixing. Lack of adequate exposure of undergraduate students in manipulation and mixing of this material, could be the reason for significant number of errors (Table 1) in mixing this material. Khajuriaet al. in 2017 compared secondary impressions made by three different materials and found that ZOE had maximum number of bubbles and cracks in comparison with light body addition silicone and polyether impression material. However, there was no significant difference in patient satisfaction level of complete dentures made by all the three materials. ${ }^{15} \mathrm{Hikmat}$ et al. conducted a similar study and found both ZOE and elastomers to be ideal for achieving secondary impression. ${ }^{16}$

Out of ten different types of errors evaluated, $97 \%$ of students performed at least one while majority of students performed three to four detectable errors in our study (Table 2). The majority of impressions had errors possibly because all the impressions assessed were made in first attempt by undergraduate students with limited clinical experience in making impressions of edentulous mouth. Thus despite all the procedures and techniques being preexplained to each student, there were significant numbers of errors observed. In this study, clinical factors such as quantity of saliva, gag reflex as well as patients co-operation were not considered. These factors could increase the difficulty of this procedure. The study 
included limited number of patients and only the maxillary arch impressions were assessed. Further studies could be done including both arches and maximum possible errors could be identified.

\section{Conclusions}

There is high possibility of including errors while making maxillary arch final impressions by undergraduate dental students. The common errors being lack of exposure of tissue stops relating to increased thickness of the material and presence of voids and creases on the impression surface. These findings emphasize the need to explore and recommend simplified techniques to learning students towards achieving precise final impressions. The inclusion of more preclinical exercises and clinical demonstrations relating to manipulation of dental materials in undergraduate curriculum may help students develop better skills in making accurate edentulous impressions.

\section{Acknowledgement}

We would like to acknowledge all final year undergraduate dental students of Nepal Medical College for providing us with maxillary arch final impressions made on their patients for assessment.

\section{References}

1. Paiva CFR, Miranda ME, Teixiera ML, Pinto JR and Olivieri KAN. Dimensional accuracy of impression material used in complete dentures. Rev Gaucha Odontol.2012; 60: 55-9.

2. Boucher CO. Complete denture impressions based upon the anatomy of the mouth. J Am Dent Assoc. 1944; 31: 1174-81.

3. Barsby M, Johnson A, Welfare R and Winstanley R. Guides to standards inprosthetic dentistrycomplete and partial dentures. London: British Society for the Study of Prosthetic Dentistry. 2005.

4. Woelfel JB, Hickey JC and Berg Jr T. Contour variations in one patient's impressions made by seven dentists. J Am Dent Assoc. 1963; 67: 1-9.
5. Al-Ahmar A, Lynch $\mathrm{CD}$, Locke $\mathrm{M}$ and Youngson C. Quality of master impressions and related materials for fabrication of complete dentures in the UK. J Oral Rehabil. 2008; 35: 111-5.

6. Petropoulos VC and Rashedi B. Current concepts and techniques in complete denture final impression procedures. J Prosthodont. 2003; 12: 280-7.

7. Duncan JP, Raghavendra S and Taylor TD. A selective-pressure impression technique for the edentulous maxilla. J Prosthet Dent. 2004; 92: 299-301.

8. Bhochhibhoya A, Acharya B, Rana SB, Sharma R, Acharya J and Maskey B. Survey of current materials and impression techniques for Complete Dentures among Nepalese Prosthodontists. J Coll Med Sc-Nepal. 2018; 14: 75-80.

9. Sun Y, Chen H, Li H, et al. Clinical evaluation of final impressions from three-dimensional printed custom trays. Scientific reports. 2017; 7: 14958.

10. Frank RP. Analysis of pressures produced during maxillary edentulous impression procedures. J Prosthet Dent. 1969; 22: 400-13.

11. Klein IE and Broner AS. Complete denture secondary impression technique to minimize distortion of ridge and border tissues. J Prosthet Dent. 1985; 54: 660-4.

12. Collett HA. Final impressions for complete dentures. J Prosthet Dent. 1970; 23: 250-64.

13. Johnson GH, Lepe $X$ and Aw TC. The effect of surface moisture on detail reproduction of elastomeric impressions. J Prosthet Dent. 2003; 90: 354-64.

14. Addison PI. Mucostatic impressions. J Am Dent Assoc. 1944; 31: 941-6.

15. Khajuria RR, Singh R, Safaya R and Hajira N. Better material for final impression in complete dentures: An in vivo study. Int J Sci Study. 2017; 5: 49-52.

16. Hikmat $\mathrm{J}$ and Al-Judy. Comparison of the effect of sectional border molding using different molding and final impression materials on the retention of maxillary complete denture bases. IOSR J Dent Med Sci. 2015; 14: 35-40. 